\title{
New Teacher Survival and Development in a Neo-liberal World
}

\author{
Adam Unwin \\ UCL Institute of Education, United Kingdom
}

\begin{abstract}
This paper explores how new teachers can understand and develop their practice in pressurized working contexts. Performativity [4] and marketization agendas foster cultures of high stakes assessment at all levels: students, teachers and schools. Presentism [10] exists in several forms with immediacy and results being foregrounded over the consideration of longer-term perspectives on learning. These factors along with teacher shortages and high turnover [16] undermine more nuanced teacher development. This paper uses data from teachers undertaking a Masters module in their newly qualified teacher (NQT) year. It found in this case that carefully designed professional development with other teachers beyond their school can counter short termism and the negative aspects of performativity and presentism. That by foregrounding the situated experiences of teachers, a 'way in' is provided for new teachers to understand more fully the complexities, dilemmas and strategies encountered in their own and others' professional practice. By thinking about and problematizing the complexities of their teaching; they are required to adopt an enquiry approach. They may be able to debate (with colleagues and students) about what alternatives might be usefully considered to the neoliberal model for education.
\end{abstract}

\section{Introduction}

The paper uses data from new teachers (in England) who were taking a Masters module during their newly qualified teacher (NQT) year. It focuses on the teachers' perspective on how their professional development happens and how they progress and develop as new teachers. This could be as 'activist professionals' $[3,17,18$, $]$ on the other hand, they might be de-professionalized, disillusioned and demoralized, so that their practice becomes a form of 'techno-bureaucracy' [2, 4, 23] utilises the term 'post-performative teacher' arguing that their developing identity is more nuanced, less binary than an 'activist' or 'techno-bureaucrat' divide.

New teachers will be aware of the contradictory perceptions of their profession, adding complexity to the ways in which their professional identity develops (Wilkins 2011: p392). To a varied extent they will aware of the neo-liberal back drop and pressures that influence many aspects of schooling
[20]. This resonates with what is explored in this paper. The development of these teachers includes their recognition of the complexity and rich interactivity of their working environments, while their understanding is influenced by being part of a wider community (beyond their own school) with other new teachers. This development is largely the result of careful pedagogic design. The purpose of this paper is to explore this pedagogic design to illustrate how teachers' situated classroom experiences can be central to enabling the development of community, practitioner debates, criticality and inquiry.

\section{Multiple contexts}

Recent research acknowledges that teacher shortages and retention are 'A longstanding problem in the teacher workforce, internationally and in the UK' [16]. This is particularly acute in the UK in urban areas and areas with socio-economic challenges [1, 19]. These new teachers often work in such schools where high staff turnover and lack of continuity can reduce local teacher community support as well as undermine positive student teacher relationships. Perryman [16] argues that it is the type of workload that is problematic:
...accountability pressures and the performativity culture in education are the major factor in teachers wanting to leave the profession. ... as teachers' work is increasingly directed towards assessment, exams, progress measures and preparation for review and inspection, and away from the more individualistic and creative aspects of the job. [16]

Hargreaves and Shirley [10] explain how presentism is a feature of school life. They build on seminal research by Lortie [13] on the nature of schoolteacher work, identifying endemic, adaptive and addictive presentism. Endemic presentism originates from on the way teaching is organized, which by its very nature is all about immediacy. Teachers are working with many students in settings which are busy, multifaceted, unpredictable and public. These complexities can inhibit engagement in long-term professional reflection. Hargreaves' research found that teachers and schools 
concentrated on short-term strategies, partially in response to initiatives from marketization agendas. Presentism stifles teacher 'rumination or inner reflection' [10] which are crucial for new teacher development. Schools and teachers get successful at implementing short term strategies which leads to an addictive presentism, at the cost of more sustainable thinking about school improvement. New teachers tend to adopt a survivalist approach [20]. Schools and colleagues may actively (if unwittingly) promote such approaches, thus embedding presentism at this early career stage.

Operating within these macro and micro contexts are the NQTs undertaking master's level continuing professional development (CPD). They work in different schools, phases and subjects. The module 'Understanding Teaching' (UT) is 'mixed mode' with face to face (f2f) sessions and online components. Three main pedagogic ideas underpin what it is trying to achieve. First, there is a clear focus on the participants' own teaching, their students, their classrooms and their schools. It is a starting point for them to engage critically with practical and theoretical educational issues by trying to make sense of their situated practice [12]. Secondly, it is about participants communicating and reflecting on their own and each other's practice. It is believed that this sharing and explaining of experiences and ideas will not only deepen understanding of the complexities at play in teaching but also encourage reflexivity. What is important is that this communication fosters the development of a community of inquiry, especially within the online groups: '...a community where individual experiences and ideas are recognized and discussed in light of societal knowledge, norms and values' [8]. The third pedagogic idea concerns a deeper understanding of the role of research in education. This entails exposure to wider debates about teaching and learning; it is also about them critically evaluating what is happening in their own classrooms.

\section{Theoretical perspectives}

This paper uses Moore's [15] work on developing reflexivity in teachers. Reflexivity requires the critical consideration of wider contexts and histories and an understanding of one's own positioning and behaviors. Reflexivity, it is argued, can be facilitated by teacher inquiry where teachers start to make sense of what is happening in their classrooms. The inquiry needs to include an understanding of the wider contexts. It also needs to be collective in that it is by being shared that it opens up discussion. This signals the importance of a teacher community. Mayes and de Freitas foreground 'the situative perspective' [14] of online communities. The pedagogic design underpinning the UT online discussions (OD) resonate with key aspects of 'communities of practice' (CoP) [12]. Students (who are all teachers) communicate and interact with each other using a shared and developing repertoire of educational language in the common endeavor: progressing their studies while also making sense of their professional (teaching) lives.

\section{Data and Analysis}

The data gathered for this research was from a sample from 6 cohorts of new teachers (total $n=32$ ). This included their accounts of participation in the UT ODs, written at the end of the first year of teaching and interviews conducted with a selection $(n=20)$ of these teachers at a later stage in their career. Any data from teachers to illustrate and exemplify the argument of the paper is attributed a number (e.g. T\#), all names of schools or teachers are pseudonyms. This data enabled the research to gain access to their feelings and voices. The research was guided by the main question: how have the ODs facilitated new teacher development? The theoretical perspective adopted for this research was interpretive with a methodological approach that used qualitative data. Analysis was assisted via thick descriptions [6].

\section{The complexity of the classroom}

This section outlines and discusses examples of the how the UT module encourages teachers to problematize their working lives. Early module activities introduce the highly interactive nature of classrooms. This quote from Watkins and Wagner [22] starts the wider thinking:

The classroom is measurably one of the most complex social situations on Earth. This statement is not made in order to mystify anything: quite the opposite - it makes sense of why simplistic approaches to classroom improvement do not work. [22]

Activities identify key reasons for this complexity. That the classroom is full of people; and people bring with them varied experiences, histories, backgrounds, abilities, disabilities, inclinations and so forth. Along with this is classrooms are interaction rich and operate as busy, multidimensional spaces where many events occur simultaneously and sometimes unpredictably [7]. The teachers engage with these concepts and perceptions of practice analyzing and sharing how they manifest themselves in their own classrooms. With and contributing to this complexity is the notion of variability. How classrooms are organized makes a huge difference to 
the learning that is accomplished. Approaches to teaching are shaped by a wide range of factors, both material (such as space, class size and available resources) and ideological or theoretical. Pedagogic approaches might be prescribed at various levels within the education system, but it is in the classroom, in the interactions of particular teachers and learners, that they are realized.

To help these new teachers start to understand better how complicated, dynamic and unpredictable classrooms are, they are also introduced to Kyriacou's [11] 'variables framework' (see fig 1). This framework could be applied to most educational situations where there are schools, teachers and students. To introduce the notion of 'variability' is to acknowledge that what happens within classrooms is by no means standard, and that it is influenced by all kinds of different factors. This includes the diversity of individuals, their varied ways of working.

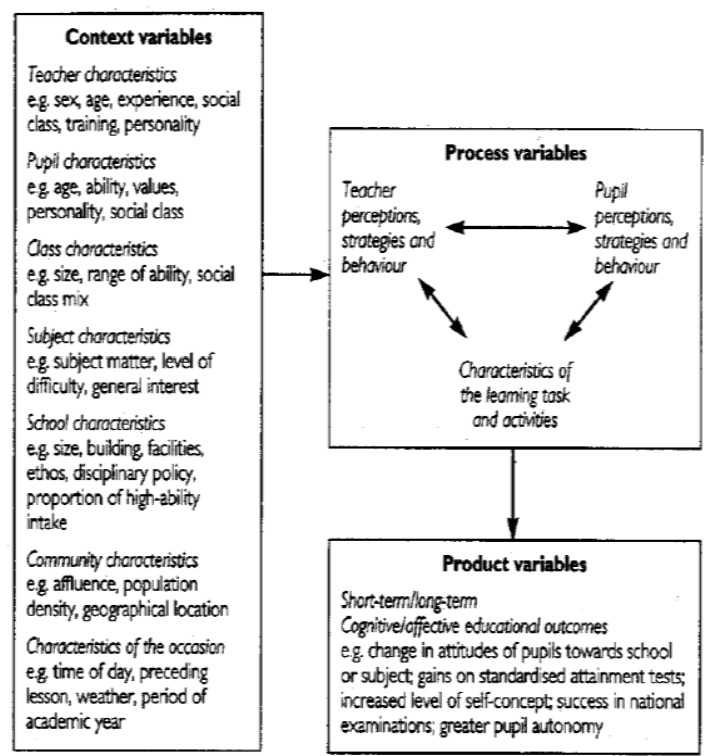

Figure 1. A basic framework for thinking about effective teaching [11]

New teachers usually can clearly see (and plan) what is happening with the 'process variables' often with pressure on them to achieve measurable outcomes 'products'. But there might be little consideration of the 'context variables'. Any effective teaching needs to start by understanding the context - and, in particular, understanding the students. What are these students interested in? Are there aspects of their culture and background that might relate to the subject? What previous understanding of the topic might they have? How do individuals and small groups behave? What friendships exist? Who might work well together, and where might there be conflicts, clashes, disagreements? These are just some of the factors about students that a teacher might want to take into account when planning. There are other context variables, too. For example: how much space is there in the classroom? How flexible are seating and tables? Does the disposition of the furniture allow for small group work? What resources are available? What time of day is it? Will the students arrive at the lesson feeling hungry or tired, excited or subdued? A teacher who is 'contextually aware' will be in a better position to come up with approaches that are effective and appropriate, for example by introducing activities that engage and interest students, and materials that relate to their lives.

On a number of occasions, I have
used the model of effective
teaching developed by Kyriacou to
reflect on classes. Knowledge of
'context variables' has helped me
to identify why strategies have
worked with one class and not
been successful with another.
(T14)

The framework also includes 'product variables'. Policymakers and politicians as well as the media often focus on 'products' of the educational system. Have exam results improved? What facts have students actually learnt? How does this align with labor-market needs? All too often they rely on league tables to compare school outcomes, making implicit and unexamined assumptions about what constitutes successful learning. Such league table and ranking systems implicitly (or often explicitly) create competition. Schools and teachers comparing themselves with other schools and teachers based on the often narrow measurable outcomes. It in this climate that marketization often occurs and performative pressures and systems become endemic. But the framework recognizes that learning is more complicated - that there are other kinds of product. Learning happens over time and often what is learned is not measured or measurable. Students might develop their confidence, their independence, understand how to work with others and find things out. These are essential life skills that are not measurable by an exam or test run at a particular time in the learning cycle. Using this framework to problematize their (and others) practice and work situations new teachers start to develop a reflexivity, a degree of trust, with shared problem solving. Importantly they start to realize that many aspects especially the context variables are outside their control. Rather than the self-blame performative systems encourage this critical awareness can be empowering and give them confidence to take a longer term and wider view of what is happening. They have more 'rumination or inner reflection' [10]. 


\section{Findings and Discussion}

These teachers have to 'get things right' quickly (control behavior, meet induction standards). Despite the presence of performative pressures and presentism undermining deeper thinking, the activities outlined above and the ongoing ODs allow and encourage reflexivity. Here a teacher encapsulates how his changing thoughts on his own practice are prompted by a peer in the OD.

..my reflective practice fixated:
between my struggle to manage
behaviour, and my determination to
put all my thought into devising
collaborative tasks and resources that
connected students with their
curriculum. Carl's writing suggested a
similar tension; his initial task,
however, focused entirely on
responses to bad behaviour. His
phrasing cast a happier light on my
behaviour-learning dilemma: my
concentration on planning rather than
behaviour wasn't a cop out; it was
proactive'. (T8)

The ODs ask participants to reflect on their practice, but not in a narrow or formulaic way. They require participants to explain and share their teaching contexts. These experiences are thus moved into a more public realm encouraging collective reaction and responsibility. Rather than being inward looking, the complexity of the classroom and the need to consider wider, longer-term perspectives is foregrounded as valid and important.

This development was facilitated by being part of a community that exposed them to different practice and different ways of looking at practice. The UT module required an inquiry approach that encouraged deeper, wider and forward thinking about practice rather than narrow, individualistic reflections about what has happened.

... a really positive aspect was having a confidential and supportive environment, with which to discuss problems or issues being faced at school. In addition I welcomed the opportunity to work collaboratively. (T9)

...gave me the confidence to include group work in my observed lesson... I found this discussion extremely rewarding, we were building on understandings of meta-cognition and collaborative learning constructed in previous conversations, I think that the interrelation of such concepts became clearer. I certainly feel more confident in my understanding of these issues than at the beginning of the year. (T12)

These new teachers were making what Moore called the 'reflexive turn' [15] becoming 'authentically and constructively critical ...challenging rather than confirmatory' (2004, p142). They were experiencing a 'pedagogy of discomfort' [5] where their educational assumptions were challenged by themselves and each other. There is a sense that their evolving identities as teachers were linked and shaped by the UT ODs. It is the shared critical discourses, particularly within the ODs, that influence their thinking and practice at this early career stage.

... it was really good to have that
contact with other NQTs, who would
have these discussions about what the
research says, and then there would
always be - but don't you find that
actually in the classroom this
happens, and this happens? And that
readymade community was really
good, because in my school there were
a couple of other NQTs, but you didn't
actually have that forum, have that
structured place to kind of discuss
things. (T28)

These new teachers have a space separate from work where they can raise issues of concern and interest. They can question school policy or microcommunity practice without feeling vulnerable, judged or compromised. They can also be honest about their progress, what they fear, what has gone wrong, what has gone well, what they find frustrating and other challenges.

The discussions allow one to voice concerns in an environment where no one will judge, as they are all going through the same difficulties. When things are going right, it is helpful to share your views with other people, as they can tell you their views and, in helping them, one feels more confident (T5)

...we were all acknowledging that we were finding it hard. And there was always that honesty there. And I really felt like I could say anything, and one of them would come up with a really good suggestion, or a probing 
question that would help me sort of unpick the situation I was in. (T9)

In the ODs they are 'listened to' and receive feedback about issues specific to them and their context. This process is underpinned by the way the ODs are designed. Participants initially present and explain aspects of their classroom practice. They receive feedback from others with threads of discussion developing. What makes this process more empowering (and perhaps less threatening) is that the online group has the added dimension of an inter-subject and inter-phase collegiality, with participants benefiting from understanding beyond their school or subject micro-community.

\section{I really liked the fact that there were more people there, doing different things, and doing different subjects, which I thought really kind of enriched your own experience, (T21)}

I was getting ideas about what was going on within other schools, and I've always thought that's been very important, to have that sort of cross fertilization between different stages and across different subjects. And I wasn't getting that at school so much, so I was getting that from the UT module (T18)

In the ODs teacher professional judgement is allowed and valued; by developing their criticality in this way at this early stage of a teaching career attributes of reflexivity are nurtured.

The collegiality is not confined to the UT group. Participants' critical engagement with practice becomes integrated into their school contexts and communities. Participants explained how the development they gained via the UT module was different from their school experiences. This teacher compares school CPD.

it wasn't as helpful as the UT Module, like, I got ten million more out of that ........because it was all about, kind of like, analysing what was going on in my classroom (T23)

They were often complimentary about aspects of school support, feeling that UT supplemented this and gave them wider perspectives: neatly summarized by one participant as the 'why' not the 'how'. Yandell explains how peripheral participation and overlapping CoPs can be difficult but provide a 'privileged vantage point... a position from which to make sense of the hurly-burly' [24].

This is happening with these new teachers: they are subject to competing pressures and expectations within their school communities (where they are novices). They are part of the UT module community. The participation within these overlapping CoPs gives them both support and the confidence to consider is happening in their schools and classes in alternative and critical ways.
As a result of the literature and
discussions for 'Developing Pedagogy' (an OD), I ended up working in collaboration with my head of department to develop 'active learning' strategies for her 'disruptive' Year 9 class. We used the work I was doing for the UT coursework as a basis to improve learning with her class. (T4)

Their participation in the UT module strengthens their school roles, giving them the self-assurance to suggest and introduce new ideas; which were often recognized as valuable and acted upon. Thus, the practitioner focus and criticality that are intrinsic parts (and outcomes) of the UT ODs gives credibility to the participants in their school communities.

New teachers may adopt a survivalist approach and concentrate on the immediate, especially if such short-term strategies are part of school ethos and practice.

...the reality of being a teacher is you are overworked and have to follow the party line, and bringing in new things is the last thing any of your colleagues wants because they are just struggling to get everything done too (T24)

...you know, NQT is sink or swim, and it is survival of the fittest. And then having this opportunity to really reflect and theorise and think deeply about what's going on, rather than just react to it, like the opportunity to be proactive was something that most NQTs aren't encouraged to do, because it's about survival. So I think that's where it was so helpful. (T17)

There is the danger the strategies provided are 'one size fits all' and expected to be implemented in a prescribed way, rather than the teacher experimenting with strategies that 'encourage teachers to question and revise their existing approaches to teaching and learning' [10]. They will 
be required to 'fit in' and 'perform'. Haggarty et al [9] argue that new teachers are expected to master behavior management and work to the norms of the school, which stymies any real development of pedagogical thinking and practice. Here a teacher explains the limitations of support at her school.

\begin{abstract}
There's not really the forum for saying let's discuss the issues that you've had and let's look at ways to challenge it. So (the ODs) for me were really helpful, because that was my biggest problem, was just feeling that I didn't know how to manage situations. And then I would get all of this input from people who were like me but in other schools, getting different types of support, so then it was like I had five or six mentors. Because in my school my mentor was feeding me the party line. So even if I did ask a different teacher I was still going to get - This is the Hillview way. (T26)
\end{abstract}

Presentism and performativity in education are exacerbated by neo-liberalism and marketization. But for these new teachers, the ODs are a crucial factor in limiting the negative effects. The way the ODs are structured allows these teachers time to engage in a more nuanced consideration of their teaching.

\begin{abstract}
This led us both to question how our teaching at times has been all about the summative assessment - either SATs or GCSEs - and we both were aware 'that you can teach just to pass tests - learning enough by rote, in the format that the children will experience it in the tests, but not really developing real understanding and problem solving skills.' Much of the discussion then focused on how this might be overcome. (T3)
\end{abstract}

The process of writing for an audience of peers provides a source of deeper 'rumination or inner reflection' [10] where participants need to think analytically about what is happening in their teaching and then present this in a meaningful and succinct way to peers. A specific and powerful example of how an OD led to new ways of seeing theoretical concepts is recounted by $\mathrm{T} 16$ he is referring to a colleague's posting and his engagement with it.

...it was his discussion of his
dissatisfaction with the term
'knowledge' that inspired me further.
Here, he quite clearly focuses on the

\begin{abstract}
shortcomings of such a restrictive term, highlighting how other participants are misled by it. He responds to my ideas, not dismissively, but rather, as I am the original source, in an effort to develop and expand the theory. I was immediately smitten with Namah's idea, believing that 'understanding' is, indeed, a far more useful and far-reaching term than knowledge. With this in mind, I have tried to implement this in the classroom and have found that thinking of a pupil's understanding is a much better way of accessing their needs in terms of where they are now and what they need to do next to further that, than reducing it to what they know, which to me now, seems somewhat restrictive. (T16)
\end{abstract}

The community and situated aspects of the ODs exposes these new teachers to different ideas and accounts of practice. This challenges the assumption there is one way or a best way of doing something when it is apparent that contexts and learners can be so diverse.

\section{Conclusion}

Developing reflexivity in teachers will counter presentism. Reflexive teachers are likely to feel uncomfortable with the short term and narrow focus of the management approaches and strategies that encourage presentism. Moreover, put simply they will 'see them for what they are', be able to critically locate them within current performativity and high stakes assessment agendas. By thinking about and problematizing the complexities of their teaching; they are required to adopt an enquiry approach. They may be able to debate (with colleagues and students) about what alternatives might be usefully considered to the neo-liberal model for education.

\section{References}

[1] Allen, R., Burgess, S. and Mayo, J. (2017) The teacher labour market, teacher turnover and disadvantaged schools: new evidence for England, Education Economics, 26 (1), 1-20.

[2] Apple, M., (2000). Can critical pedagogies interrupt Rightist policies? Educational theory, 50 (2), 229-254.

[3] Avis, J., (2005). Beyond performativity: reflections on activist professionalism and the labour process in further education. Journal of education policy, 20 (2), 209-222. 
[4] Ball, S.J. (2003) The teacher's soul and the terrors of performativity', Journal of Education Policy, Vol.18 (2), pp.215-228.

[5] Boler, M. (1999). Feeling Power: Emotions and Education. Routledge, New York and London,

[6] Creswell, J. and Miller, D. (2000) 'Determining Validity in Qualitative Inquiry Getting Good Qualitative Data to Improve Educational Practice'. Theory into Practice 39 (3), pp.124-130.

[7] Doyle, W. (1980). Classroom Management. West Lafayette, IN: Kappa Delta Pi.

[8] Garrison, D. and Anderson, T (2003). E-Learning in the 21st Century: A Framework for Research and Practice. Routledge-Falmer, London,

[9] Haggarty et al. (2011) Haggarty, L., Postlethwaite, K., Diment, K. and Ellins, J. (2011). 'Improving the learning of newly qualified teachers in the induction year'. British Educational Research Journal, 37 (6), 935-954

[10] Hargreaves, A and Shirley, D (2009), 'The Persistence of Presentism' Teachers College Record, Volume 111 Number 11, p. 2505-2534

[11] Kyriacou, C. (2009), Effective Teaching in Schools: Theory and Practice. Cheltenham: Stanley Thornes

[12] Lave, J. and Wenger, E. (1991). Situated Learning: Legitimate Peripheral Participation. Cambridge: Cambridge University Press.

[13] Lortie, R., (1975) Schoolteacher. Chicago, IL: University of Chicago Press.

[14] Mayes, T. and de Freitas, S, (2004) JISC eLearning Models Desk Study Stage 2: Review of elearning theories, frameworks and models. JISC,

[15] Moore, A. (2004). The Good Teacher: Dominant discourses in teaching and teacher education. London: Routledge

[16] Perryman, J and Calvert, G (2019) What motivates people to Teach, and why do they leave? Accountability, performativity and teacher Retention, British Journal of Educational Studies, DOI: $10.1080 / 00071005.2019 .1589417$.

[17] Sachs, J., 2000. The activist professional. Journal of educational change, 1 (1), 77-95.

[18] Sachs, J., 2003. The activist professional. Buckingham: Open University Press.
[19] Sims, S. and Allen, R. (2018) Identifying schools with high usage and high loss of newly qualified teachers, National Institute Economic Review, 243 (1), R27-R36.doi:10.1177/002795 011824300112.

[20] Unwin, A., Yandell, J., (2016). Rethinking Education: Whose knowledge is it anyway? New Internationalist. 